\title{
Prevalence of Anaemia Among Young Adult Females in Two Selected Grama Niladhari Areas in the Southern Province of Sri Lanka
}

\author{
Samamalee Upekshi Kankanamge, ${ }^{1,}$, Sameera Ariyarathna ${ }^{1}$, Poruthotage Pradeep Rasika Perera ${ }^{2}$ \\ ${ }^{1}$ Department of Allied Health Sciences, Faculty of Medical Sciences, University of Sri Jayewardenepura, Gangodawila, Sri Lanka \\ ${ }^{2}$ Department of Biochemistry, Faculty of Medical Sciences, University of Sri Jayewardenepura, Gangodawila, Sri Lanka
}

Email address:

samamlee@ymail.com (S. U. Kankanamge), sameera.ariyarathna@gmail.com (S. Ariyarathna), rasika@sjp.ac.lk (P. P. R. Perera)

${ }^{*}$ Corresponding author

\section{To cite this article:}

Samamalee Upekshi Kankanamge, Sameera Ariyarathna, Poruthotage Pradeep Rasika Perera. Prevalence of Anaemia Among Young Adult Females in Two Selected Grama Niladhari Areas in the Southern Province of Sri Lanka. Science Journal of Public Health.

Vol. 4, No. 6, 2016, pp. 430-434. doi: 10.11648/j.sjph.20160406.12

Received: August 15, 2016; Accepted: August 24, 2016; Published: September 10, 2016

\begin{abstract}
Anaemia is a global health problem and its impact is felt in Sri Lanka as well. Anaemia is characterized by less than the normal quantity of hemoglobin in the blood. Anaemia occurs at all stages of life, but is particularly prevalent in women of reproductive age, pregnant women and children. This study was conducted to investigate the prevalence of anaemia in two rapidly developing administrative units in Southern Province of Sri Lanka. A cross-sectional study was conducted in Hungama and Hiththatiya middle administrative units in the Hambantota and Matara districts of Southern province of Sri Lanka. Females between 20-50 years of age $(\mathrm{n}=152$ from each area) were selected by simple random sampling and $2 \mathrm{ml}$ of venous blood was withdrawn from each subject and analysed for haemoglobin concentration by cyanmethaemoglobin method. Anaemia was defined as a haemoglobin level less than $115.0 \mathrm{~g} / \mathrm{L}$. Overall prevalence of anaemia (Haemoglobin $<114.9 \mathrm{~g} / \mathrm{L})$ was $3.94 \%$ and $5.26 \%$ for Hiththatiya middle and Hungama grama niladhari areas, respectively. There was no significant difference between prevalence of anaemia in the two administrative units $(\mathrm{P}>0.05)$. Age wise $87.5 \%$ of anaemic people are over 40 years. Prevalence of anaemia is significantly less in the two Grama Niladhari areas compared to national data and there is no statistically significant difference between the prevalence of anaemia between the two areas. Thus there may be pockets in Sri Lanka where anaemia may not be a major health problem as compared to the rest of the country.
\end{abstract}

Keywords: Haemoglobin (Hb), Anaemia, Females

\section{Introduction}

Anaemia is a global public health problem that affects populations in both developed and developing countries [1]. According to a review of nationally representative survey data from 1993-2005, the World Health Organization (WHO) estimates that more than 1.62 billion people are affected by anemia [1]. Anemia occurs at all stages of life, but is particularly prevalent in women of reproductive age, pregnant women and children. It occurs as a consequence of deficiencies in the production of mature circulating red blood cells or of excessive loss or destruction of these cells [2]. Anemia is characterized by a decrease in the normal number of red blood cells or less than the normal quantity of hemoglobin in the blood. The etiology of anemia is multifaceted and often several factors are at play in an anemic individual. Nutritional anemia as a result of iron deficiency is the most common cause of anemia worldwide [3].

Anaemia is one of most prevalent pathological conditions in Sri Lanka. According to many recent studies, more than one fourth of Sri Lankan people are suffering from anaemia [4]. Out of them, women are more likely to be anaemic due to their menstrual bleeding, poor nutritional status and delivery. The two administrative units (Grama Niladhari areas) selected situated in tow of the most rapidly developing areas of Sri Lanka. With urbanization and development the dietary habits of the population change and this could lead to 
nutritional problems including anaemia. Thus the study was conducted to assess the prevalence of anaemia as a baseline to observe its variations, if any, in the two selected administrative units within the Hambantota and Matara districts in Sri Lanka, in the future.

\section{Methods}

\subsection{Subjects}

The study was conducted in Hungama and Hiththatiya middle grama niladhari areas (administrative units) in the Hambantota and Matara districts of the Southern Province of Sri Lanka, in the year 2012. The anaemic status was assessed using $\mathrm{Hb}$ concentration. Healthy females in the age group 2050 years were randomly selected to the study as the study population. All healthy females in the age group of 20-50 years who gave consent were taken into the study and pregnant women, females who have chronic diseases (e.g. Diabetes Mellitus, Hypertension) and females who were suffering from acute infections (e.g. fever) were excluded.

\subsection{Sampling}

The houses were selected by systematic random sampling. Every third house in the grama niladhari list was selected. Subsequently, the selection of the individuals for the study was done by visiting those selected homes. From each household, one to three healthy individuals in the age group of 20-50 years were selected randomly. The number of healthy females selected from each grama niladhari area was 152. A sample of 304 healthy females representing both Hiththatiya middle and Hungama grama niladhari areas were recruited to this study. The prevalence of iron deficiency anemia (IDA) in females of Sri Lanka was reported as $36 \%$ in a National Survey [5]. Therefore, Sample size was targeted for a $36 \%$ anaemic prevalence rate within a $95 \%$ confidence interval and it was estimated at 152 . Therefore, from each grama niladhari area, 152 individuals were randomly selected to achieve a sample of 304 females.

\subsection{Data Collection}

Interviewer administered questionnaires were used to obtain the background data with regard to anaemia. Suitable females were selected considering the inclusion and exclusion criteria. Informed consent was obtained from all individuals selected for the study before interviewing and withdrawing blood. 0.002 litres $(0.002 \mathrm{~L})$ of venous blood was withdrawn from each subject by a qualified nurse, under aseptic conditions using disposable syringes. Blood was collected into vacutainer tubes and transported within 24 hour of collection in a cold box at about 4 centigrade for laboratory analysis of haemoglobin. The concentration of haemoglobin was measured by photometric cyanmethaemoglobin method. Disposable syringes/needles were used in blood withdrawing \& wastes were disposed in a proper way.

\subsection{Laboratory Analysis}

Blood is diluted in the ICSH (International Council for Standardization Haematology) reagent based on Drabkin's reagent. This contains potassium ferricyanide, potassium cyanide and a non-ionic detergent. Red cells are lysed and the released haemoglobin is reduced to methaemoglobin by potassium ferricyanide and then methaemoglobin reacts with potassium cyanide to form cyanmethaemoglobin complex. Formation of cyanmethaemoglobin complex is directly proportional to the haemoglobin content of whole blood, when measured at $540 \mathrm{~nm}$. Calibration curve was plotted using series of haemoglobin standard with Drabkin's reagent. Absorbance was read using UV spectrophotometer at $540 \mathrm{~nm}$ wave length. After preparing calibration curve, all test specimen of blood were analyzed. Five micro litres of whole blood was mixed thoroughly with 0.00125 L of Drabkin's reagent in an eppendorf tube. Absorbance was read after 10 minutes at $540 \mathrm{~nm}$. Haemoglobin concentration was measured using the calibration curve. Quality control was performed to ensure accuracy of data and unknown samples from another laboratory was assayed as a further way of ensuring quality. The biochemical tests were conducted at the research laboratory, Faculty of Medical Sciences, University of Sri Jayewardenepura.

\subsection{Ethical Approval}

The study protocol was approved by the Ethical Review Committee of the Faculty of Medical sciences, University of Sri Jayewardenepura, Sri Lanka. The participants were fully explained about the nature of the study and informed written consent were obtained. The privacy of the research participants and the confidentiality of data provided by them were completely protected. Data was securely stored and was available only to the investigator/supervisor and data is not divulged to any third party. Participants were entirely free to clarify any problems they had regarding the study at any time. Withdrawing blood was done by a qualified nurse, under aseptic conditions to minimize potential risks to the participants. Individuals detected with low haemoglobin concentration (anaemia) were referred for medical advice for the management of the condition.

\subsection{Statistical Analysis}

Data analysis was done using a computer based statistical package, SPSS (version 15). Descriptive statistical methods were used to describe and summarize the sample characteristics. Pearson correlation test and chi-square test were used as significant tests as when required. A p-value of $<0.05$ was taken as the significant probability level.

\section{Results}

The age of the study population ranged from 20-50 years. Average age of the subjects was 38 years. The total number of individuals who participated in the study was 304. From each grama niladhari area 152 individuals participated. 
According to socio-demographic background data we obtained, the age group 46-50 years shows the higher contribution in the study sample in both areas $32.9 \%$ and $39.5 \%$ ). And more than $50 \%$ of study sample represents $36-$ 50 years of age. When considering civil status, more than
$75 \%$ of study sample are married in both areas. In Hungama, the higher percentage of married people (35.8\%) has two children. But in Hiththatiya Middle, most married people $(33.3 \%)$ are having three children (Table 1$)$.

Table 1. Distribution of demographic characteristics of the study populations of the two Grama Niladhari areas.

\begin{tabular}{|c|c|c|c|c|}
\hline Characteristics & Frequency in Hiththatiya Middle & $\%$ & Frequency in Hungama & $\%$ \\
\hline Age group & $\mathrm{n}=152$ & & $\mathrm{n}=152$ & \\
\hline $20-25$ & 19 & 12.5 & 19 & 12.5 \\
\hline $26-30$ & 21 & 13.8 & 14 & 9.2 \\
\hline $31-35$ & 22 & 14.5 & 17 & 11.2 \\
\hline $36-40$ & 18 & 11.8 & 19 & 12.5 \\
\hline $41-45$ & 22 & 14.5 & 23 & 15.1 \\
\hline \multicolumn{5}{|l|}{ Civil status } \\
\hline Married & 120 & 78.9 & 134 & 88.2 \\
\hline Unmarried & 32 & 21.1 & 17 & 11.2 \\
\hline Separated & 0 & 0 & 1 & 0.6 \\
\hline No. of living children & $\mathrm{n}=120$ & & $\mathrm{n}=134$ & \\
\hline One & 24 & 20 & 28 & 20.9 \\
\hline Three & 40 & 33.3 & 31 & 23.1 \\
\hline Four/more & 21 & 17.5 & 24 & 18 \\
\hline No child & 2 & 1.7 & 3 & 2.2 \\
\hline Menstruation & $\mathrm{n}=152$ & & $\mathrm{n}=152$ & \\
\hline Regular & 109 & 71.7 & 97 & 63.8 \\
\hline Irregular & 18 & 11.8 & 22 & 14.5 \\
\hline Menopause & 25 & 16.5 & 33 & 21.7 \\
\hline
\end{tabular}

The overall prevalence of anaemia $(\mathrm{Hb}<114.9 \mathrm{~g} / \mathrm{L})$ was $3.94 \%$ and $5.26 \%$ for Hiththatiya middle and Hungama grama niladhari areas, respectively (Table 2).

Table 2. Distribution of anaemic and non-anaemic individuals in the two selected areas based on the different cut-off points used in other similar studies and the present study.

\begin{tabular}{|c|c|c|c|c|}
\hline & $\begin{array}{l}\text { Non-anaemic }(\%)(\mathrm{Hb}<114.9 \\
\text { g/L) }\end{array}$ & $\begin{array}{l}\text { Anaemic }(\%)(\mathrm{Hb}<114.9 \\
\mathrm{g} / \mathrm{L})\end{array}$ & $\begin{array}{l}\text { Anaemic }(\%)(\mathrm{Hb}<110.0 \\
\mathrm{g} / \mathrm{L})\end{array}$ & $\begin{array}{l}\text { Anaemic }(\%)(\mathrm{Hb}<120.0 \\
\mathrm{g} / \mathrm{L})\end{array}$ \\
\hline Hiththatiya middle & 96.06 & 3.94 & 0.66 & 9.21 \\
\hline Hungama & 94.74 & 5.26 & 1.97 & 12.50 \\
\hline
\end{tabular}

Similar studies conducted in different areas of Sri Lanka have used different cut-off points [Table 2]. Other similar studies conducted in Kadugannawa division, and Galle district in Sri Lanka, have used anaemic cut-off points as less than $110.0 \mathrm{~g} / \mathrm{L}$ and $120.0 \mathrm{~g} / \mathrm{L}$ for haemoglobin respectively [Table 2]. When considering the results obtained from the present study, the prevalence of anaemia in both grama niladhari areas were $5.26 \%$ in Hungama and $3.94 \%$ in Hiththatiya-Middle based on the cut-off point less than 114.9 $\mathrm{g} / \mathrm{L}$ for haemoglobin.

Data with regard to menstruation shows that more than $60 \%$ are having regular monthly cycle in both areas. But $14.5 \%$ in Hungama and $11.8 \%$ in Hiththatiya Middle, show irregular menstruation. When anaemic females in the two areas were analysed, in Hungama, 37.5\% of anaemic people have regular menstrual bleeding. Females who have attained menopause comprise $37.5 \%$ of the anaemic population and only $25 \%$ of anaemic people are having menstrual irregularities [Table 3].
Table 3. Nature of menstruation in anaemic population of the two selected areas.

\begin{tabular}{llll}
\hline & Regular (\%) & Irregular (\%) & Menopause (\%) \\
\hline $\begin{array}{l}\text { Hiththatiya } \\
\text { middle }\end{array}$ & 66.6 & 16.7 & 16.7 \\
Hungama & 37.5 & 25 & 37.5 \\
\hline
\end{tabular}

Regarding the age, $87.5 \%$ of anaemic people are over 40 years. When focusing on Hiththatiya area, $66.6 \%$ of anaemic women have regular menstruation and, percentage of both irregular and post-menopausal women are same (16.7\%). Compared to Hungama $50 \%$ of anaemic population is over 40 years. Majority of anaemic females (12 out of 14) are having 2 or more children whereas the other two are without any children. Mean $\mathrm{Hb}$ concentration is higher in Hiththatiya Middle than Hungama grama niladhari area. There are no statistically significant differences in any of the above variables between Hungama and Hiththatiya Middle. 
Table 4. Haemoglobin concentrations of participants in the two selected areas.

\begin{tabular}{llll}
\hline Variable & Hiththatiya Middle & Hungama & p-value* \\
\hline Haemoglobin $(\mathrm{g} / \mathrm{d})$ & & & \\
Mean & 13.21 & 12.98 & 0.584 \\
SD & 0.87 & 0.97 & \\
\hline
\end{tabular}

${ }^{*}$ Comparing Hiththatiya and Hungama areas (based on Pearson chi-square test)

The mean $\mathrm{Hb}$ concentration in Hiththatiya was somewhat greater than mean $\mathrm{Hb}$ level in Hungama $(132.1 \mathrm{~g} / \mathrm{L}$ in Hiththatiya and $129.8 \mathrm{~g} / \mathrm{L}$ in Hungama). But, there was no significant statistical difference between the prevalence of anaemia among two grama niladhari areas, according to ChiSquare test $(\mathrm{P}$ value $=0.584>0.05)$ [Table 4$]$.

\section{Discussion}

This study primarily focused on anaemia in a female population in two rapidly developing grama niladhari areas in the southern province of Sri Lanka. Prevalence of anaemia is significantly less in the two Grama Niladhari areas compared to national data and there is no statistically significant difference between the prevalence of anaemia between the two areas. Thus there may be pockets in Sri Lanka where anaemia may not be a major health problem as compared to the rest of the country.

According to socio-demographic background data we obtained, most volunteers were in the age group 46-50 years in both areas. And more than $50 \%$ of study sample represents the age group 36-50 years. Anaemia was defined in this study as a haemoglobin level less than $115.0 \mathrm{~g} / \mathrm{L}$ according to a study published in Journal of Pakistan Medical Association [6]. But some similar studies conducted in Sri Lanka have used different cut-off points [Table 2]. When considering the results obtained from the study, the prevalence of anaemia in both grama niladhari areas was surprisingly low (5.26\% in Hungama and $3.94 \%$ in Hiththatiya-Middle). These values are not comparable with similar studies carried out in Sri Lanka and shows considerably very low prevalence than those findings [Table 2].

According to such a study conducted in Kadugannawa division, Sri Lanka, $20 \%$ of participants were anaemic under the cut-off point of $110.0 \mathrm{~g} / \mathrm{L}$ for haemoglobin. But it consisted of both males and females (190) with a total population of 399. Anaemic population found in the present study is considerably very low $(1.97 \%$ in Hungama and $0.66 \%$ in Hiththatiya-Middle) when compared to the data obtained from the study conducted in Kadugannawa division [Table 2]. The mean age of females was 46.5 years. Among females, $14 \%$ of population showed menorrhagia [7]. Similarly in our study, age group 46-50 years shows the highest contribution to anaemia in the study sample in both areas $(32.9 \%$ \& $39.5 \%)$ and $14.5 \%$ in Hungama and $11.8 \%$ in Hiththatiya, show irregular menstruation. But, data with regard to menstruation shows that more than $60 \%$ of women are having regular monthly cycle in both areas. Data obtained regarding menstruation vary between the study areas. In Hungama, $25 \%$ of anaemic people are having menstrual irregularity which was defined as menorrhagia (abnormally heavy bleeding) and irregular cycle lengths (cycle lengths less than 21 days or longer than 35 days). When focusing on Hiththatiya area, $66.6 \%$ of anaemic women have regular menstruation.

According to a study conducted in Galle District, in the Southern province of Sri Lanka, $64.7 \%$ of total study population were females and the prevalence of anaemia $(\mathrm{Hb}$ $<120.0 \mathrm{~g} / \mathrm{L}$ ) was $58.1 \%$ among them [5]. The value obtained from the present study shows very low prevalence when comparing with the study conducted in Galle district $(9.21 \%$ in Hiththatiya and $12.5 \%$ in Hungama) [Table 2]. However that study has been conducted among adolescents of age 1216 years.

A cross-sectional survey was conducted in Mumbai between October 1993 and December 1995, prevalence of anaemia $(\mathrm{Hb}<120.0 \mathrm{~g} / \mathrm{L})$ is $82.2 \%$ in non-pregnant women [8]. In the present study $9.21 \%$ population in Hiththatiya and $12.5 \%$ population in Hungama fell below recommended value [Table 2]. It shows considerably lower prevalence of anaemia in the present study.

According to a study conducted in Lahore, in the province of Panjab of Pakistan, the prevalence of anaemia $(\mathrm{Hb}<115.0$ $\mathrm{g} / \mathrm{L}$ ) was $64.3 \%$ [6]. The value obtained from the present study shows very low prevalence $(5.26 \%$ in Hungama and $3.94 \%$ in Hiththatiya-Middle) when comparing with the study conducted in Lahore, Pakistan [Table 2]. However that study has been conducted among patients admitted in the medical and surgical wards of Mayo Hospital, Lahore.

\section{Conclusions}

The present study demonstrates that the prevalence of anaemia in women between the ages of 20-50 years in two administrative units in Southern province of Sri Lanka. Overall prevalence of anaemia (Haemoglobin $<114.9 \mathrm{~g} / \mathrm{L}$ ) was $3.94 \%$ and $5.26 \%$ for Hiththatiya middle and Hungama grama niladhari areas, respectively. The prevalence of anaemia in both study areas is significantly less compared to national data. The mean $\mathrm{Hb}$ concentration in Hiththatiya was somewhat greater than mean $\mathrm{Hb}$ level in Hungama (132.1 $\mathrm{g} / \mathrm{L}$ in Hiththatiya and $129.8 \mathrm{~g} / \mathrm{L}$ in Hungama). There was no significant difference between prevalence of anaemia in the two administrative units $(\mathrm{P}>0.05)$. Age wise $87.5 \%$ of anaemic people are over 40 years. Thus there may be pockets in Sri Lanka where anaemia may not be a major health problem as compared to the rest of the country.

\section{Acknowledgement}

Census data are what imperative in conducting a survey; Authors would like to thank both administrative officers of Hungama and Hiththatiya - Middle, who provided the grama niladhari list and for their co-operation in conducting this study. 


\section{References}

[1] Organization, W. H., Worldwide prevalence of anaemia 19932005: WHO global database on anaemia. 2008.

[2] Campbell K, Anemia- causes and treatment, Nursing Times, 2003; 99 (43): 30.

[3] Charles, C. V.; Summerlee, A. J.; Dewey, C. E., Anemia in Cambodia: Prevalence, etiology and research needs. Asia Pacific journal of clinical nutrition 2012, 21 (2), 171-181.

[4] Jayathissa R, National Food Security Survey (NFSS), Current Nutritional status of children in Sri Lanka, Sri Lanka Nutrition Bulletin; 2009; 1: 5.

[5] Hettiarachchi M, Liyanage C, Wickremasinghe R, Hilmers D $\mathrm{C}$, Prevalence and severity of micronutrient deficiency, a cross-sectional study among adolescents in Sri Lanka, Asia Pacific journal of clinical nutrition, 2006; 15: 56-63.

[6] Butt Z, Ashfaq U, Sherazi S F H, Jan N U, Diagnostic accuracy of "pallor" for detecting mild and severe anaemia in hospitalized patients, Journal of Pakistan Medical Association, 2010; 60: 762-5.

[7] Ranasinghe A W, Cuncheer S, Determination of iron status in a rural population in Sri Lanka, Prevalence of anemia and oral manifestations, Proceedings of the Annual Research Sessions, University of Peradeniya, Sri Lanka: 1996; 87-90.

[8] Loretta B, Sarala N, Alka G, Sharad G, and Alka K, Prevalence of anemia and its determinants among nonpregnant and pregnant women in India, Food Nutrition Bulletin; September 1998; 19 no: 205-209

[9] Bowes M, Detsky A S, The relation of conjunctival pallor to the presence of anemia, Journal of General Internal Medicine, 1997; 12: 102-106.

[10] Athukorala T M S, De Silva L D R, Iron status of adolescent females in three schools in an urban area of Sri Lanka, Journal of Tropical Pediatrics, 1990; 36: 316-321.

[11] de Silva A, Atukorala S, Weerasinghe I, Ahluwalia N, Iron supplementation improves iron status and reduces morbidity in children with or without upper respiratory tract infections, a randomized controlled study in Colombo, Sri Lanka, The American journal of clinical nutrition, 2003; 77: 234-241.

[12] Batista M, Souza A I D, Miglioli T C, Santos M C D, Anemia and obesity, a paradox of the nutritional transition in Brazil, Cadernos de Saúde Pública, 2008; 24: s247-s257.

[13] Ghosh R and Bharati P, Haemoglobin status of adult women of two ethnic groups living in a peri-urban area of Kolkata city, India, a micro-level study, Asia Pacific Journal of Clinical Nutrition, 2003; 12: 451-459.

[14] Hyder S M, Persson L A, Chowdhury A M R, EkstroÈm E C, Anaemia among non-pregnant women in rural Bangladesh, Public health nutrition, 2001; 4: 79-83.

[15] Jayatissa R, Ranbanda R M, Prevalence of challenging nutritional problems among adolescents in Sri Lanka, Food and Nutrition Bulletin, 2006; 27: 153-160.

[16] Liyanage C E, Thabrew M I, Goonaratne C, Iron deficiency anaemia in children aged 9-24 months a rural area in South of Sri Lanka, Sri Lanka Dental Journal, 1995; 24: 59-65.

[17] Mc Lean E, Cogswell M, Egli I, Wojdyla D, de Benoist B, Worldwide prevalence of anaemia, WHO vitamin and mineral nutrition information system, 1993-2005, Public health nutrition, 2009; 12: 444-454.

[18] Verma A, Rawal V S, Kedia G, Kumar D, Chauhan J, Factors influencing anaemia among girls of school going age (6-18 years) from the Slums of Ahmedabad city, Indian Journal of Community Medicine, 2004; 29: 25-26.

[19] WHO/UNICEF/UNITED NATION UNIVERSITY, Iron deficiency anaemia, assessment, prevention and control, a guide for programme managers, 2001. 